\title{
Health and Work Capacity of Older Adults: Estimates and Implications for Social Security Policy
}

\author{
August 2013 \\ David M. Cutler, Harvard University and NBER \\ Ellen Meara, Dartmouth College and NBER \\ Seth Richards-Shubik, Carnegie Mellon University and NBER
}

\begin{abstract}
The simultaneous growth in longevity and mounting budget deficits in the U.S. have increased interest in raising the age of eligibility for public health and retirement benefits. The consequences of this policy depend on the health of the near elderly, and on the distribution of health by demographic group. We simulate the work capacity and likely disability experience of near elderly individuals (62-64 year-olds) based on the work, disability, and retirement status of slightly younger people. Our estimates, from two distinct data sets, indicate that work capacity is substantial at this age. Because health deteriorates very slowly from ages 60-65, labor force participation could rise by 15-20 percent for all demographic groups, while overall disability rates would change very little. However, less advantaged groups would face challenges in the labor market. The expected earnings of current non-workers without any college education are lower than similar workers, by 15 to 25 percent, indicating the uneven burden of changes in the age of eligibility.
\end{abstract}

This work was supported by a grant from the Sloan Foundation. In addition, some research reported herein was pursuant to a grant from the U.S. Social Security Administration (SSA) funded as part of the Retirement Research Consortium (RRC). The findings and conclusions expressed are solely those of the authors and do not represent the views of SSA, any agency of the Federal Government, the RRC, or NBER. We gratefully acknowledge Bob Willis for comments on an earlier draft. Paul Horak and Willie Powell provided expert research assistance. 
The long-range deficit in Social Security requires reform to bring future benefits and revenues into alignment. Similar concerns surround Medicare, a program for which budget forecasts are even more dire. One common suggestion for reform of both programs is to increase the age of early and normal retirement (Munnell et al. 2004), a suggestion described in detail by the bipartisan National Commission on Fiscal Responsibility and Reform (National Commission on Fiscal Responsibility and Reform 2010). Analysts argue that this is good policy because people are living longer and are healthier at any given age than in the past, thus making employment at older ages more feasible (Munnell et al. 2004; Steuerle, Spiro and Johnson 1999).

The equity implications of raising the age of eligibility may be troubling, however. People with poor health will find the return to increased work substantially more difficult than people with better health, both because they cannot work as much, and because they earn less when they do work. Since health varies systematically by socioeconomic group, these differences could be important. In this paper, we examine the potential impact of policies that would raise the age of eligibility for early and normal retirement benefits and for Medicare eligibility on work capacity and disability of different groups. Our basic question is: If eligibility ages for public programs increase, would more people go to work, or would more people instead be out of work and classified as disabled? If the latter, how does this vary by demographic group?

To answer this question, we simulate the labor force and disability participation of people aged 62-64, using their own health status and the relationship between health and work status of people just younger than them. We assume that the relationship between health and an individual's capacity to work is the same among people aged 62 to 64 (the ages at which individuals can currently claim early entitlement for Social Security benefits) as it is for people 
aged 57 to 61 . Thus, by estimating the impact of health on labor force participation among people aged 57 to 61, we can forecast work capacity for people aged 62 to 64 . If private pension and health benefits, as well as employment opportunities, became the same for ages just above and below 62, this would predict actual labor market impacts of these changes. However we interpret our results as a measure of capacity rather than actual behavioral changes, so our analysis does not rely on this assumption. We do the same exercise for self-reported disability.

Our primary empirical finding is that health deteriorates very slowly in the 60s. In particular, the health of people aged 62 to 64 is only marginally worse than the health of people aged 57 to 61, and virtually indistinguishable from the health of individuals aged 59 to 61 . This is true overall and for most demographic groups. It is also true through age 69. As a result, when we simulate the work capacity of people aged 62 and older and assume that there were similar job opportunities and no differential financial consequences to working, we find that labor force participation in these ages would increase by about 15 or more percentage points for most demographic groups, while self-reported disability rates would increase relatively little.

However, among less educated adults aged 62 to 64, the expected earnings of current non-workers predicted to work if the early eligibility age (EEA) were raised to 65 are 15 to 25 percent lower than the earnings of current workers aged 62 to 64 . Finally, disability rates would rise more for the less educated than among older adults with some college education. For some groups, the increase in disability could be substantial, as much as 6 percentage points (a 60 percent increase). And since life expectancy is shorter for these groups, the percentage reduction in healthy, non-working years at the end of life is higher - a reduction of 9 percent among less educated men and women compared with 6.5 percent for the better educated. Thus, the equity implications of such a change would be unfavorable. 
The paper is structured as follows. Section 1 discusses past research on health and work capacity. Section 2 describes the data we analyze. Section 3 presents descriptive calculations of health for different race, gender, and education groups. Section 4 estimates models of work capacity and simulates labor force status in the wake of alternative Social Security and Medicare changes in age eligibility. Section 5 discusses the implications of these results.

\section{Section 1. Background}

There is a large literature on determinants of retirement decisions and the consequences of retirement policy for that decision. Much of this work has been summarized in Gustman and Steinmeier (2005) and Blau and Goodstein (2010). We focus our summary on the potential impact of proposed policies to raise the early and normal retirement age for Social Security benefits and age-eligibility for Medicare benefits. Although there is controversy regarding the exact role Social Security benefits play in retirement decisions, a few points of consensus emerge. First, most of the literature finds that health shocks, although important determinants of work, do not explain retirement trends over time, partly because few individuals have truly poor health (Burkhauser, Couch and Phillips 1996; McGeary 2009; Mitchell and Phillips 2000; Smith 1999). Second, Social Security policies cannot explain large declines in labor force participation through 1990, but changes in rules that make work relatively more favorable may have contributed to rising labor force participation in recent years (Blau and Goodstein 2010; Gustman and Steinmeier 1986; Gustman and Steinmeier 2005; Lumsdaine, James and David 1996; Lumsdaine, Stock and Wise 1994; Rust and Phelan 1997). Recent evidence on proposed (rather than actual) policy change comes from simulations of the impact of several policy changes among singles and married couples without private pension benefits. Van der Klaauw 
and Wolpin predict large increases in employment rates among married males aged 62-69 (10 percentage points for raising the EEA to 70 and 15 points for the elimination of all benefits before 70), but only modest changes among married females and single males or females. Gustman and Steinmeier (2005) simulate that if the EEA were raised to 64, the share of 62-63 year olds who would be retired would fall by 5 percentage points. Finally, health insurance benefits provided by employers also influence labor force participation, as does Medicare eligibility, but modestly (Blau and Gilleskie 2008; Gustman and Steinmeier 1994; Lumsdaine, James and David 1996).

Because retirement rates spike at ages 62 and, more moderately at 65 , much of the retirement literature attempts to model these peaks at ages 62 and 65 as a function of pension and/or health benefits. Since delaying retirement from 62 to 65 is approximately actuarially fair, the literature cannot attribute the spike in retirement at age 62 to the incentive effects of Social Security. Thus, researchers need other explanations to understand why people retire when they do (Blau and Goodstein 2010; Borsch-Supan 1999; Gustman and Steinmeier 1986; Gustman and Steinmeier 2005; Rust and Phelan 1997).

Gustman and Steinmeier (1986; 2005) posit that discounting is the issue. Their key insight is that individuals with high discount rates (i.e. they discount the future heavily) will retire as soon as early retirement benefits are permitted at age 62. For individuals with low discount rates, retirement is optimal when the actuarial adjustment to delayed SSA benefits become less favorable, at age 65 . An alternative model suggests that individuals would like to retire before 62, but due to market imperfections that leave them unable to borrow against future income, they "wait" until age 62 and retire at rapid rates (Rust and Phelan 1997). Rust and Phelan argue similarly that retirement spikes at age 65 reflect a lack of access to health insurance 
in private markets that is relieved with age eligibility for Medicare.

Most relevant to our work is the literature focusing on health status and/or health insurance and retirement. A study of older male workers in the Health and Retirement Study (HRS) describes characteristics of Social Security beneficiaries claiming early retirement (Burkhauser, Couch and Phillips 1996). In the HRS, early retirees were slightly more likely to be in poor health than non-early retirees, but only $3 \%$ of the early retirees reported poor health. Reports of poor health were much more predictive of adverse economic outcomes (such as low employment rates, low levels of income and wealth) than early retirement. In closely related work, McClellan (1998) demonstrates that functional status, rather than a health condition, is an important determinant of retirement decisions. This finding is not surprising given the heterogeneity in outcomes among individuals with a particular health condition. Mitchell and Phillips (2000) also explore potential changes in age eligibility for Social Security, carefully assessing streams of income, the availability of disability benefits, pension benefits, and health insurance individuals can expect over their lifetimes. On the basis of behavioral responses to the possible change in financial incentives, they estimate that retirement would fall by much more than disability would rise. McGarry (2004) uses the Health and Retirement Study to show that one's perception of health is an important determinant of retirement.

The literature described above aims to understand what people might do in response to policy changes, and in each case authors are forced to make strong assumptions regarding an individual's ability to borrow against future Social Security Benefits, or to restrict empirical populations to narrow groups such as working single males from a single firm or people facing a similar ability to access pension and health benefits, to overcome some of the complexity introduced by joint decisions and by variation in private retiree benefits. However, the literature 
in this area fails to answer an important question regarding the potential burden of reforms that raise the age of eligibility for retirement and health benefits: what are the young retired able to do?

Our work focuses on this question and thus complements existing studies of health and retirement. Further, our analysis does not force us to restrict our study population in order to avoid complicated private pension rules or make assumptions about liquidity constraints.

Because we model a rise in the Early Eligibility Age to 65, our simulation does not rely on the resolution of the debate regarding whether Medicare benefits induce the spike in retirement at age 65, or whether the financial implications of postponing retirement after age 65 can explain these spikes. Rather, we focus on capacity, not simulating expected behavior. Finally, we focus more attention on the distributional impact of such policy changes by describing how these rules may impact sex, race, and education groups differentially.

\section{Data to Estimate Health and Work Capacity}

To match health limitations and conditions with labor force status, we use data from two complimentary sources: the Medical Expenditure Panel Survey (MEPS) and the Health and Retirement Study (HRS) (Ezzeti, Rohde, and Greenblatt 2008; Hauser and Willis 2005). The MEPS is a nationally representative household survey with an overlapping panel design. It has been run since 1996. New panels are drawn each year from the National Health Interview Survey and then followed for two years. We complement estimates from the MEPS with the HRS, a panel study of adults age 50 and older, which began in 1992.

Both surveys ask questions about health insurance, labor force participation, physical and mental health and functioning, demographics, disability status, and household characteristics. 
Both surveys also include a rich set of demographics (exact age, gender, race, ethnicity, education, geographic information) and information on self-reported health and functional limitations. Still, there are some differences that make each one worthwhile.

\section{MEPS Data}

Our MEPS sample comes from the public-use Full-Year Consolidated Data files for 2000-2003. We use those years because the MEPS included a 100-point self-reported health scale at that time. Respondents were shown a thermometer with markings from 0 to 100 and asked to "indicate on this scale how good or bad your own health is today, in your opinion." The fine-grained responses to this question allow tight links between self-perceptions of health and reported labor market behavior.

The MEPS also asks detailed questions on impairments in activities of daily living (ADLs) and instrumental activities of daily living (IADLs), as well as other physical, cognitive, and social limitations. ${ }^{1}$ In addition, the MEPS asks whether individuals have ever been diagnosed with certain health conditions such as diabetes, heart conditions, stroke, or high blood pressure. Together with information on current smoking status and body mass index (BMI), these measures provide a very rich picture of health status.

We restrict attention to blacks, whites, and Hispanics aged 57 and older, for which there

\footnotetext{
${ }^{1}$ Activities of Daily Living (ADL) indicate a "yes" response to the following question, "Does anyone in the family receive help or supervision with personal care such as bathing, dressing, or getting around the house?" Similarly, instrumental ADLs, or IADLs, are derived from the response to whether anyone in family received help or supervision with IADLs such as using the telephone, paying bills, taking medications, preparing light meals, doing laundry, or going shopping. (The specific individual is identified in a later question.) Physical functional limitations include: difficulty reaching overhead, bending or stooping, standing 20 minutes, walking 3 blocks, walking up 10 steps, or lifting 10 pounds. Impairments were based on questions about whether anyone in family had difficulty seeing (vision), hearing, or if anyone had cognitive limitations regarding confusion, memory loss, trouble with decision-making, or if individuals needed supervision for their safety. Social limitations indicate that respondent is "limited in participating in social, recreational or family activities because of an impairment or a physical or mental health problem."
} 
are 22,026 observations on 14,145 individuals. After dropping observations without data on key variables, our final MEPS sample contains 18,732 observations on 12,410 individuals. ${ }^{2}$

Data describing whether individuals are "in the labor force,” "retired,” or "disabled" come from two questions. First, individuals were asked, "Do you currently have a job for pay or own a business?" If the answer is no, respondents were asked, "What is the main reason you did not work since (START DATE)?” Possible responses include: could not find work; retired; unable to work because ill/disabled; on temporary layoff; maternity/paternity leave; going to school; take care of home or family; wanted some time off; or waiting to start new job. We classify individuals as disabled if they self-report "unable to work because ill/disabled” and term them retired if they self-report being "retired, " if they never worked in their life, say they are "taking care of home or family," or give an unclassified reason for not being employed. ${ }^{3}$ All other individuals are coded as "in the labor force."

\section{HRS Data}

We complement the MEPS with data from the HRS. The HRS is representative of the entire community-dwelling population aged 50 and older. We focus on adults aged 55 to 74 , those most likely to work, including 14,679 females and 10,985 males. Our models of work capacity (from which we later predict labor force status) focus on 5,449 males and 7,403 females aged 59-61, whom we observe in 1994-2008.

The HRS has a larger sample of older adults than the MEPS, with richer information on

\footnotetext{
${ }^{2} 3,083$ observations were dropped because respondents did not complete the form with the self-reported health scale. Survey weights are provided that adjust for this non-response. An additional 211 observations were dropped due to missing information on education or labor force status.

${ }^{3}$ These data represent each individual's subjective assessment of disability and retirement status. Given our interest in self-perceived well being, we believe this is more appropriate than defining disability and retirement status based on benefits receipt or some threshold in hours of work.
} 
economic and household characteristics and the characteristics of one's spouse. Thus, we can simulate work capacity for 62 to 64 year olds based on the health and work status of 59 to 61 year olds, arguably a better comparison group than all adults aged 57 to 61 . The HRS asks about a common measure of depression symptoms, the 8 item Community Epidemiological Scale of Depression, ${ }^{4}$ and unlike the MEPS, the HRS asks about former smoking status as well as current status. Thus, we can include risk factors as a measure of health. The disadvantage of the HRS is that self-reported health is only characterized on a five-point scale: excellent, very good, good, fair, and poor.

To measure labor force status in the HRS, we use the question: "Are you working now, temporarily laid off, unemployed and looking for work, disabled and unable to work, retired, a homemaker, or what?" Individuals who were working, laid off, unemployed, or "partially retired" are coded "in the labor force". Individuals who described themselves as "retired" are coded as "retired". Individuals self-reporting that they were disabled are included as "disabled", in addition to those who reported applying for or receiving Social Security Disability Insurance. Note that defining disability in this way is, if anything, likely yields an upper bound on rates of disability by age since some individuals may rationalize their decisions to exit the labor force by reporting they are disabled.

Data on labor force participation in the two surveys are presented in the first rows of Table 1. The share of individuals who are in the labor force declines rapidly between ages 57-61 (59-61) and 65-69, falling by about half. In both data sets, the share retired increases commensurately. Few people are disabled past age 65, in large part because individuals eligible

\footnotetext{
${ }^{4}$ Physical functional limitation measures include whether respondent has difficulty with walking one/several blocks; jogging 1 mile, sitting 2+ hours, rising from a chair; climbing stairs; stopping/kneeling/crouching, carrying weights over 10 pounds, or picking up a dime. ADLs include five questions on whether respondents need help with dressing, walking across the room, bathing, eating, getting into or out of bed. IADLs indicate whether respondent has difficulty with managing meals, groceries, or medications.
} 
for full retirement benefits are no longer considered disabled. Officially, such individuals would be transferred onto retirement benefits, and impaired individuals in those ages likely report themselves as retired.

Demographic averages for each survey are presented in Appendix Table A1. Both surveys are representative of the US population when weighted.

\section{The Self-Reported Health Status of Older Adults}

We begin our empirical analysis by describing the age profile of self-reported health status. The remaining rows of Table 1 show health measures by age and survey. The 100 point scale of self-rated health in the MEPS shows virtually no change from ages 57-61 through age 69. It falls by only 1 point over these ages. Similarly, the share of individuals reporting "Fair" or "Poor" health in the HRS rises by about 1 percentage point over these ages.

Self reported measures of function change slowly over these ages as well. Although rates of ADL and IADL limitations double in the MEPS from ages 57-61 to ages-69, less than 5 percent of people aged 65-69 in the MEPS have an ADL or IADL limitation. Under 10 percent of people aged 65-69 in the HRS have an ADL or IADL limitation. Thus, overall, health appears to remain fairly constant through the sixties.

As people enter their 70s, health starts to decline. The thermometer rating of health in the MEPS falls by 6 points from the late 60s to the 70s, and the share of the population in excellent or very good health in the HRS falls more rapidly after age 70 as well.

For our analysis, we care about health both overall and for different demographic groups. Accordingly, we move to a demographic decomposition. We describe groups separately by education (those attending college versus those with a high school degree or less education), 
which is determined early in life, in addition to gender and race/ethnicity (white non-Hispanic, black non-Hispanic, and Hispanic). Thus, the membership of the groups is determined well before the minimum age for our analyses.

Figures 1 and 2 show the averages of self-rated health over ages 50 to 85 . Figure 1 shows health for men, and figure 2 shows health for women. Within each cell, we plot the average thermometer score at each age from the MEPS and the share of people in excellent, very good, or good health from the HRS.

There are clear differences in the level of health by gender, education and race/ethnicity. Within any gender and education group, average health for whites is higher than for blacks and for Hispanics. Similarly, the better educated report better health than the less educated, holding constant gender and race/ethnicity. The magnitude of the differences varies by group, with the largest gaps showing for white college attendees compared with blacks or Hispanics with less education. Scores for men and women reveal modestly better health for women, despite the significant longevity advantage for women.

Looking at the age profiles, we see again that self-reported health changes very little over ages 50-69. Among white, college educated women and men, for example, the health scale is virtually constant at 80 throughout the age range. Although the average health scale for less educated white women and men is slightly lower, between 70 and 74 , the trend is also flat over this age range. The data for blacks and Hispanics are noisier, but show similar patterns.

\section{Estimating Work Capacity}

In this section, we consider additional dimensions of health and examine how the multiple dimensions of health taken together are related to labor force participation. We then use 
these results to forecast what would happen to the fraction of people who would self-identify as in the labor force, disabled, or retired under a policy change that reduces the availability of current retirement benefits.

While not a formal simulation model, our analysis is motivated by a hypothetical policy change that would increase the early eligibility age for Social Security benefits from age 62 to age 65, set the age of full Social Security benefits at age $70,{ }^{5}$ and raise the age of Medicare eligibility to 70 . For a more complete simulation we would need to model private pensions and health insurance policies, along with overall labor demand. Since we do not do this, we refer to our results as work capacity, rather than as an expected behavioral response to reform.

We analyze work capacity for those aged 62-64, who would face a delay in eligibility for early retirement benefits under this policy. To understand work capacity, disability, and retirement for this group, we estimate labor force participation models for currently non-eligible people near age 62. In the MEPS sample, we consider people aged 57-61 year olds. With the larger HRS data, we use people aged 59-61. We model the three outcomes of labor force participation, retirement (R), and disability (D) using multinomial logit models. In this framework, the probability of disability can be expressed as:

$$
\operatorname{Pr}(\text { Disabled })_{i}=\frac{\exp \left(x_{i}^{\prime} \beta_{D}\right)}{1+\exp \left(x_{i}^{\prime} \beta_{R}\right)+\exp \left(x_{i}^{\prime} \beta_{D}\right)}
$$

After estimating (1) on the population under age 62, we use the parameter estimates from the model, and the independent variables from the 62-64 year old population to predict labor force status for people aged 62-64. Since we have the same independent variables for the older group as for the younger group, we can form this prediction at the individual level. We then average the predictions overall, and by gender, race/ethnicity, and education.

\footnotetext{
${ }^{5}$ Among the adults aged 65-66 observed in 2000 to 2003, the normal retirement age is rising to 67 but is still somewhat below it.
} 
This analysis assumes that the health conditions and measures of functional status used in our models are similar for individuals 1 to 6 years apart in age. That is, reporting a health score of 80 means the same thing for a 64 year old as it does for a 59 year old. ${ }^{6}$ This assumption is problematic if individuals norm self-reported health according to their age group, or if the severity of a diagnosed condition differs by age in ways that are not captured by the health index or the functional limitations studied here.

Using the MEPS data, we estimate the models separately by sex. The health variables include a cubic function of the 100-point health scale, indicators for physical or mental limitations (such as any ADL or IADL limitations), sensory impairments, and diagnoses for common health conditions and risk factors, coded as shown in Table 1. In addition to these health variables, as well as demographics like education, race, ethnicity, marital status, and Census division of residence (coded as in Appendix Table A1), all models control for year of interview. The HRS models are generally similar to the MEPS models, with a few exceptions. HRS models use indicators of self-reported health status (Very Good, Good, Fair, or Poor relative to Excellent) rather than the 100-point health scale, unavailable in the HRS. In addition, the HRS models include more detail along some dimensions such as the presence of additional health conditions, more detail on household composition, and economic indicators for an individual's occupation (blue collar, low skill services, versus other), health insurance coverage (for self, or spouse), and pension coverage (any versus none).

Work Capacity Among Individuals 62-64

\footnotetext{
${ }^{6}$ Van Doorslaer and Jones (2003) provide evidence supporting this assumption. They examine the relationship between a typical, categorical, self-reported health variable and a more objective index based on eight functional status questions. They find that the means and implied thresholds of the index within each self-reported health category are similar for two broad age groups: 18-44 and 45+.
} 
Before we present multinomial logit models of labor force status, we describe how labor force participation and self-reported disability vary by self-reported health status in figures 3 and 4. The relationship between health status and disability rates is nonlinear, but generally speaking, a 10 point decline in the 100 point health scale accompanies a rise in disability of 2 to 5 percentage points near the top of the health scale, and closer to a 10 percentage point increase in disability as one moves below 60 on the health scale. Among 59-61 year olds in the HRS as well, there is a non-linear relationship between self-reported health and labor force participation. Participation is low for people with fair or poor health, and flattens out above that. The same is true, in the opposite direction, for reported disability. A notable finding in both data sets is that labor force participation and disability change very little over the top half of the health scales. This suggests that work capacity remains very high for the vast majority of older adults, given relatively high ratings of health in the MEPS and the HRS samples.

Appendix table A2 reports relative risk ratios from multinomial logit models of labor force status in the MEPS. The 100-point health scale has a strong association with self-reported disability, with a risk ratio of .51 for males and .56 for females for each 10 points on the linear health scale. Given the higher order terms, the relationship between the thermometer scale of health and labor force status is non-linear. We plot the relationship between labor force participation, disability, and health scores in Figure 3.

Comparable multinomial results for the HRS population aged 59-61 are reported in Appendix table A3. Several indicators for health limitations, impairments, or conditions are strongly associated with self-reported disability. Being in poor self-rated health has a very large impact on reported disability, as do functional limitations and a variety of specific conditions. Figure 4 shows the relationship between self-reported health and retirement and disability for the 
population aged 59-61.

The MEPS and HRS data both show that health variables are much less predictive for retirement than they are for disability. Functional limitations, ADLs or IADLs lead to a greater probability of retirement in the MEPS, but the effects are generally smaller than for disability. None of the non-health variables are significantly associated with retirement for males. For females, college education is associated with lower retirement, as is being unmarried. Hispanics are more likely to be retired than non-Hispanics.

Figure 5 compares the simulated proportion of people aged 62-64 who are in the labor force or disabled with the observed percentage. This figure shows predictions for the MEPS and HRS samples; the numeric results for each are reported in Appendix table A4. Two patterns stand out. First, the predicted rise in labor force participation is large, exceeding 10 percentage points for most groups and 20 percentage points among some groups.

Second, the pattern for disability is quite variable by group. In the MEPS, the fraction of less educated white males who are disabled increases by 5 percentage points in the absence of early eligibility for Social Security benefits - a 60 percent relative increase. Less educated black males would also witness a 7 percentage point rise in disability rates in the MEPS.

The HRS results show little or no rise in disability rates among most groups, with the exception of black males and females in lower education groups, among whom disability rises by 3 to 5 percentage points. For several groups in the HRS, the models predict, if anything, lower disability among 62 to 64 year olds. This is predominantly due to low rates of reported ADLs/IADLs at these ages. Overall, despite some large relative increases in self-reported disability, the share of individuals likely to report they are disabled would remain very low, less than 10 percent among college attendees, and 20 percent or lower among the remaining 
individuals.

\section{Earnings among individuals simulated to be in the labor force}

An important question for individuals who would delay retirement is what they would likely earn were they to work. To examine this question, we use the detailed information on earnings in the HRS to simulate the earnings of non-working individuals aged 62 to 64 based on the earnings of workers 59-61. Our model is similar to equation (1), except that the dependent variable is the earnings of current workers. We estimated these models using generalized linear models with a log link function to account for the log normal distribution of earnings while permitting us to use model parameters to predict earnings, rather than the natural log of earnings. We then predicted earnings for each individual aged 62-64 in the older population. ${ }^{7}$

To compare predicted earnings of non-workers likely to be affected by any increase in the EEA to actual earnings of currently employed workers age 62-64, we take a weighted average of the predicted earnings for non-workers, where the weight for each non-worker is his/her predicted probability of entering the labor force from our earlier simulation. We focus these results on less educated workers in each sex, race, and ethnicity group, since these potential workers tend to have fewer labor market prospects. All earnings are expressed in constant 2002 dollars based on the Consumer Price Index. Effectively, we ask the question, "Would workers who are induced to stay in the labor force because of an increase in the EEA likely earn much less than individuals who currently work at these ages?”

On the basis of health and demographic information, the answer, shown in Table 2

\footnotetext{
${ }^{7}$ To compare simulated earnings with actual earnings of people aged 62-64, we need to adjust for average earnings differences as individuals age. We make such an adjustment using the ratio of average earnings of working 62-64 years olds to the predicted earnings based on the model from 59-61 year olds. For estimates reflecting predicted earnings and the difference between predicted earnings of non-workers and actual earnings of workers, we report bootstrapped standard errors.
} 
appears to be "Yes." The table shows earnings comparisons for the less educated groups, for whom these differences would be the greatest concern. ${ }^{8}$ Average earnings for current 62-64 year-old low education workers (row 1 ) range from $\$ 17,000$ to $\$ 33,000$, depending on race and gender. The predicted earnings of those who may be induced to work if Social Security EEA was raised to age 65 are generally lower (the second row of the table). As the third row shows, these predicted earnings are 15 to 25 percent lower than the actual earnings of those currently in the labor force.

For women, the situation is similar. Average earnings are lower for women than for men, but the difference in predicted earnings of those not in the labor force is roughly the same range: 15-20 percent. Thus, the earnings consequences of this change would be significant. The lower earnings for non-participants may offer some insight into why these workers have chosen early retirement instead of labor market participation.

\section{Expected retirement years and changes in lifetime benefits}

These findings have implications for the progressivity of the retirement system. Since less educated people and racial/ethnic minorities live less long than their counterparts, reductions in retirement years for these groups are a greater reduction in lifetime welfare. To show these implications quantitatively, we consider how raising the Social Security and Medicare eligibility ages would affect the expected amount of time spent in retirement. To do this, we calculate the expected retirement years (ERY) for each demographic group currently, and compare this to the ERY using the predicted labor market status in our simulations.

We form ERY as the number of years a person alive at a given age can expect to spend retired. Defining survival probabilities as $\pi_{g, a \mid x}$ for group g at age a, conditional on being alive

\footnotetext{
${ }^{8}$ We find similar results for more educated groups.
} 
at age $\mathrm{x}$, and the fraction of the group that is retired at each age as $r_{g, a}$, ERY is defined as:

$$
\mathrm{ERY}_{g, x}=\sum_{a=x}^{\infty} \pi_{g, a \mid x} r_{g, a}
$$

If monthly benefits remain approximately the same for each group, changes in lifetime benefits amounts will be closely related to changes in the length of retirement.

To obtain survival probabilities, we use the nearly universal sample of death certificates compiled in the Mortality, Multiple-Cause-of-Death (MCD) file for 2000 (see Meara, Richards and Cutler 2008). This gives us death totals by age, gender, race/ethnicity, and education. We match these with population estimates from the Public-Use Micro Sample of the 2000 Census to calculate mortality rates for each group. Although there are known inconsistencies with the education levels reported on death certificates relative to self-reports while alive (Sorlie and Johnson, 1996), these data allow the use of two broad educational categories with reasonable accuracy: high school or less vs. any college. ${ }^{9}$

Table 3 shows the loss of retirement years from this policy. For brevity, we display only results from the MEPS data; the patterns are similar within the HRS. Because the expected increase in labor force participation is relatively similar across groups, the expected reduction in retirement years is similar as well. Among whites, the simulated reduction in expected retirement years is 0.6 for men with a high school degree or less, and 0.5 for men with any college education. ${ }^{10}$

As a percentage of current expected years in retirement, however, the changes are very different. Because the better educated live so much longer than the less educated, the proportional loss in retirement years is greater for the less educated (5 percent) than for the better

\footnotetext{
${ }^{9}$ For further details on these data sources and education measurement, see Meara, Richards, and Cutler (2008).

${ }^{10}$ To understand why ERY could decrease by only 0.5 when the EEA increases by three years, recall that in our simulations the share retired at ages 62-64 drops by about 0.2. Thus 0.2 times three years is approximately the change in ERY.
} 
educated (3 percent). A similar differential is apparent for women, for the same reason.

If we only count years in retirement from age 65, when Social Security benefits would be received under the new policy, the proportional loss is 9 percent for less-educated white males and females and 6.5 percent for the high-education groups. ${ }^{11}$ All else equal, this change would reduce the progressivity of the Social Security system.

\section{Conclusion and Discussion}

In this paper, we simulated the work capacity of individuals in age groups targeted by policies that raise the age of eligibility for Social Security. Specifically, we examined a circumstance equivalent to increasing the age of early eligibility for Social Security to 65 (instead of 62) and no change in the age of full eligibility. Our primary output is work capacity what the people in this age group would do differently from their current status using only the fact that their health is different from those of younger aged individuals.

We find that until age 70, health appears to decline very slowly, and thus work capacity is large. Our results suggest that, based upon the health of today's young retirees, 15 to 20 percent more individuals could work than currently do. However, rates of new disability may increase. We estimate that about 2 to 6 percent of the population would report disability in this circumstance.

To put our findings in context, consider the drop in labor force participation between 1970 and 1994 (Burkhauser, Couch and Phillips, 1996). Between 1970 and 1994, the percentage of 63-year old men in the labor force fell by 24 percentage points. At age 68, the drop was 17

${ }^{11}$ Our calculation assumes that current retirees aged 62-64 all receive Social Security retirement benefits, which is supported by evidence that only a small number of eligible retirees delay claiming benefits. Coile et al. (2002) show that only $10 \%$ of men who retire before age 62 delay claiming benefits by more than one year after their $62^{\text {nd }}$ birthday, and fewer than $5 \%$ of those who retire after age 62 delay claiming by more than one year. 
percentage points. This is roughly the same as our estimate of additional work capacity at those ages assuming that only health status changed across ages. Thus, our analysis suggests that work capacity is just as high now as actual labor force participation was several decades ago.

On the downside, however, there are significant disparities in these findings across groups, and the earnings capacity of less educated older adults who may be induced to work with a raise in the EEA is significantly lower than for current workers. The simulated rise in disability is large for blacks and people who never attended college. Indeed, as much as 6 percent of this group does not have the capacity to work at ages 62-64 due to their poor health. For other groups, the simulated rise in disability is smaller at 3 percentage points, but this is still a considerable amount relative to their baseline rates. In addition, raising the ages of eligibility for partial Social Security benefits disproportionately reduces the expected retirement years of the less educated and racial minorities. The potential rise in disability suggests the need for alternative sources of income among older workers, especially older workers facing higher risk of disability or barriers to work.

Despite these concerns, our results offer reasons to be cautiously optimistic about the ability for many older Americans to continue working beyond current retirement ages. We find that the good health enjoyed by individuals aging throughout their 60s implies a tremendous potential for labor force participation. Even among those groups that would observe the highest disability rates under a policy that delayed early retirement until age 65, the majority of individuals aged 62 to 64 could work, based on their reported health status. If workers translate this good health, and a new norm of providing public retirement benefits at older ages into longer working lives, such a shift has the potential to both reduce the costs of the Social Security program and to increase revenue raised through payroll and income taxes that would not be 
realized in the absence of such a policy change. 


\section{REFERENCES}

Blau, D.M. and D.B. Gilleskie. 2008. "The Role of Retiree Health Insurance in the Employment Behavior of Older Men." International Economic Review 49(2):475-514.

Blau,D.M. and R.M. Goodstein. 2010. "Can Social Security Explain Trends in Labor Force Participation of Older Men in the United States?" Journal of Human Resources 45(2):328-363.

Borsch-Supan, A. 1999. "Incentive Effects of Social Security Under an Uncertain Disability Option." National Bureau of Economic Research Working Paper Series No. 7339.

Burkhauser, R.V., K.A. Couch, and J.W. Phillips. 1996. "Who takes early Social Security benefits? The economic and health characteristics of early beneficiaries." Gerontologist 36(6):789-799.

Coile, C., P. Diamond, J. Gruber, and A. Jousten. 2002. "Delays in Claiming Social Security Benefits," Journal of Public Economics 84(3): 357-385.

Ezzati-Rice, T.M., F. Rohde, and J. Greenblatt. 2008. "Sample Design of the Medical Expenditure Panel Survey Household Component, 1998-2007." Methodology Report No. 22. Agency for Healthcare Research and Quality, accessed November 21, 2012 at http://meps.ahrq.gov/mepsweb/data_files/publications/mr22/mr22.pdf.

Gustman, A.L. and T.L. Steinmeier. 1986. "A structural retirement model." Econometrica 54:555-584.

Gustman, A.L. and T.L. Steinmeier. 1994. "Employer-Provided Health Insurance and Retirement Behavior." Industrial and Labor Relations Review 48(1):124-140.

- . 2005. "The social security early entitlement age in a structural model of retirement and wealth." Journal of Public Economics 89(2-3):441-463.

Hauser, R.M. and R.J. Willis. 2005. "Survey Design and Methodology in the Health and Retirement Study and the Wisconsin Longitudinal Study." This is an electronic version of an article published in Aging, Health, and Public Policy: Demographic and Economic Perspectives, a supplement to Population and Development Review Volume 30. New York: Population Council, 2005.

Lumsdaine, R.L., J.H. Stock, and D.A.Wise. 1996. "Why Are Retirement Rates So High at Age 65?" Pp. 61-82 in Advances in the Economics of Aging, edited by D.A. Wise. Cambridge: National Bureau of Economic Research, Inc.

Lumsdaine, R.L., J.H. Stock, and D.A. Wise. 1994. "Pension Plan Provisions and Retirement: Men and Women, Medicare, and Models." Pp. 183-212 in Studies in the Economics of Aging, edited by D.A. Wise. Chicago: University of Chicago Press.

McClellan, M.B. 1998. "Health Events, Health Insurance, and Labor Supply: Evidence from the Health and Retirement Study." Pp. 301-350 in Frontiers in the Economics of Aging, edited by A.W. David. Chicago: University of Chicago Press.

McGarry, K.A. 2004. "Health and Retirement: Do Changes in Health Affect Retirement Expectations?" Journal of Human Resources 39(4):624-648.

McGeary, K.A. 2009. "How do health shocks influence retirement decisions?" Review of Economics of the Household 7:307-321.

Meara, E.R., S. Richards, and D.M. Cutler. 2008. "The gap gets bigger: changes in mortality and life expectancy, by education, 1981-2000." Health Aff (Millwood) 27(2):350-360.

Mitchell, O.S. and J.W.R. Phillips. 2000. "Retirement Responses to Early Social Security Benefit Reductions." National Bureau of Economic Research Working Paper Series No. 7963. 
Munnell, A., H., K.B. Meme, N.A. Jivan, and K.E. Cahill. 2004. "Should We Raise Social Security's Earliest Eligibility Age?": Center for Retirement Research.

National Commission on Fiscal Responsibility and Reform. 2010. The Moment of Truth: Report of the National Commission on FIscal Responsbility and Reform. The White House.

Accessed November 21, 2012 at http://www.fiscalcommission.gov/sites/fiscalcommission.gov/files/documents/TheMome ntofTruth12_1_2010.pdf

Rust, J., and C. Phelan. 1997. "How Social Security and Medicare Affect Retirement Behavior in a World of Incomplete Markets." Econometrica 65(4):781-832.

Smith, J.P. 1999. "Healthy Bodies and Thick Wallets: The Dual Relation between Health and Economic Status." Journal of Economic Perspectives 13(2):145-166.

Sorlie, P.D.and N.J. Johnson. 1996. "Validity of education information on the death certificate." Epidemiology 7(4):437-439.

Steuerle, C.E., C. Spiro, and R.W. Johnson. 1999. "Can Americans Work Longer?" in Straight Talk on Social Security and Retirement Policy. Washington, D.C.: Urban Institute.

Van Der Klaauw, W. and K.I. Wolpin. 2005. "Social Security and the Retirement and Savings Behavior of Low Income Households." Penn Institute for Economic Research, Department of Economics, University of Pennsylvania.

Van Doorslaer, E. and A.M. Jones. 2003. "Inequalities in self-reported health: validation of a new approach to measurement." Journal of Health Economics 22: 61-87. 
Figure 1: Average Health Scale in the MEPS and HRS, Males

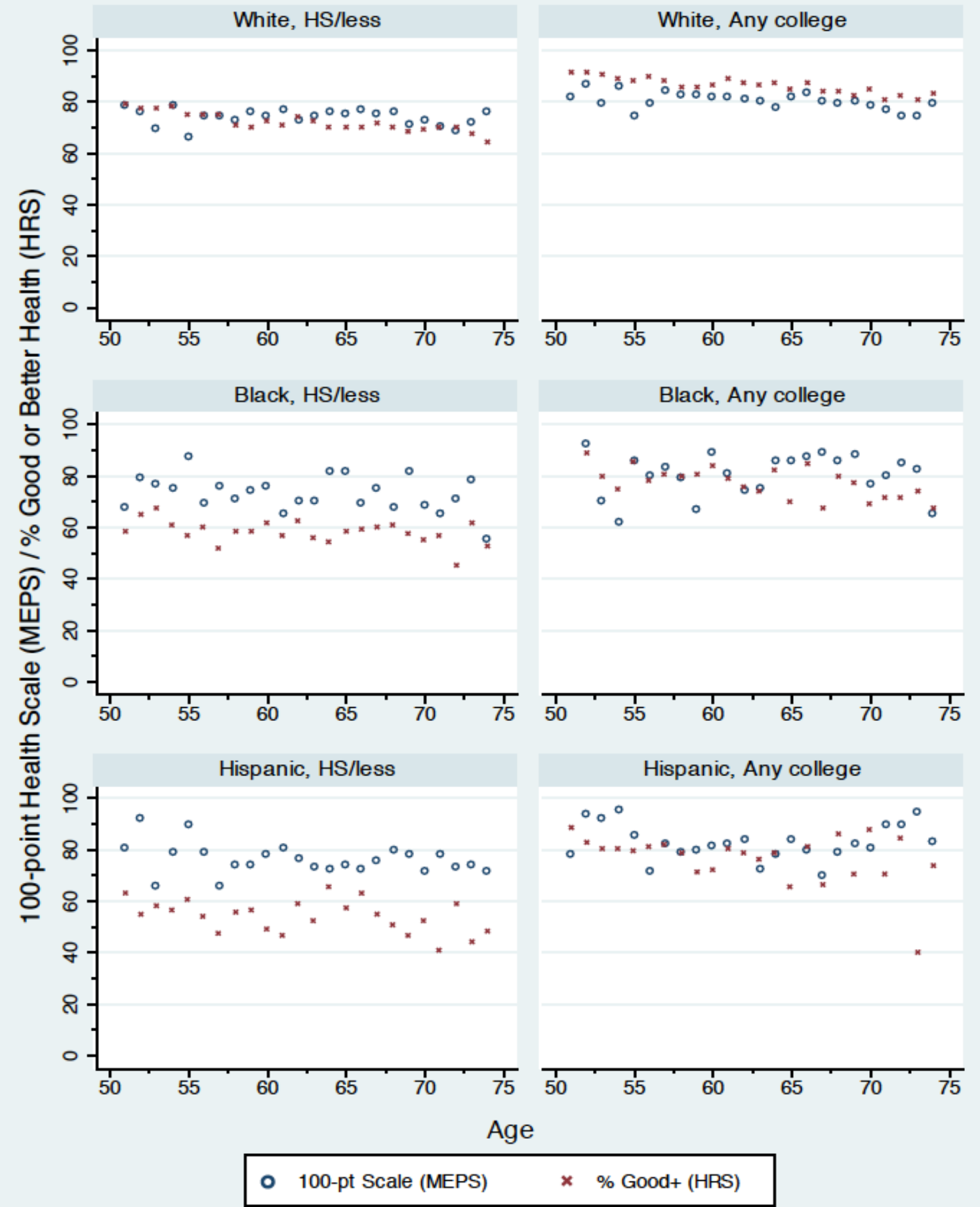

The chart shows the average thermometer score by age and demographic group in the MEPS (age 55-84), and the share of people reporting good, very good, or excellent health in the HRS (age 55-74). All data are weighted to national totals. 
Figure 2: Average Health Scale in the MEPS and HRS, Females

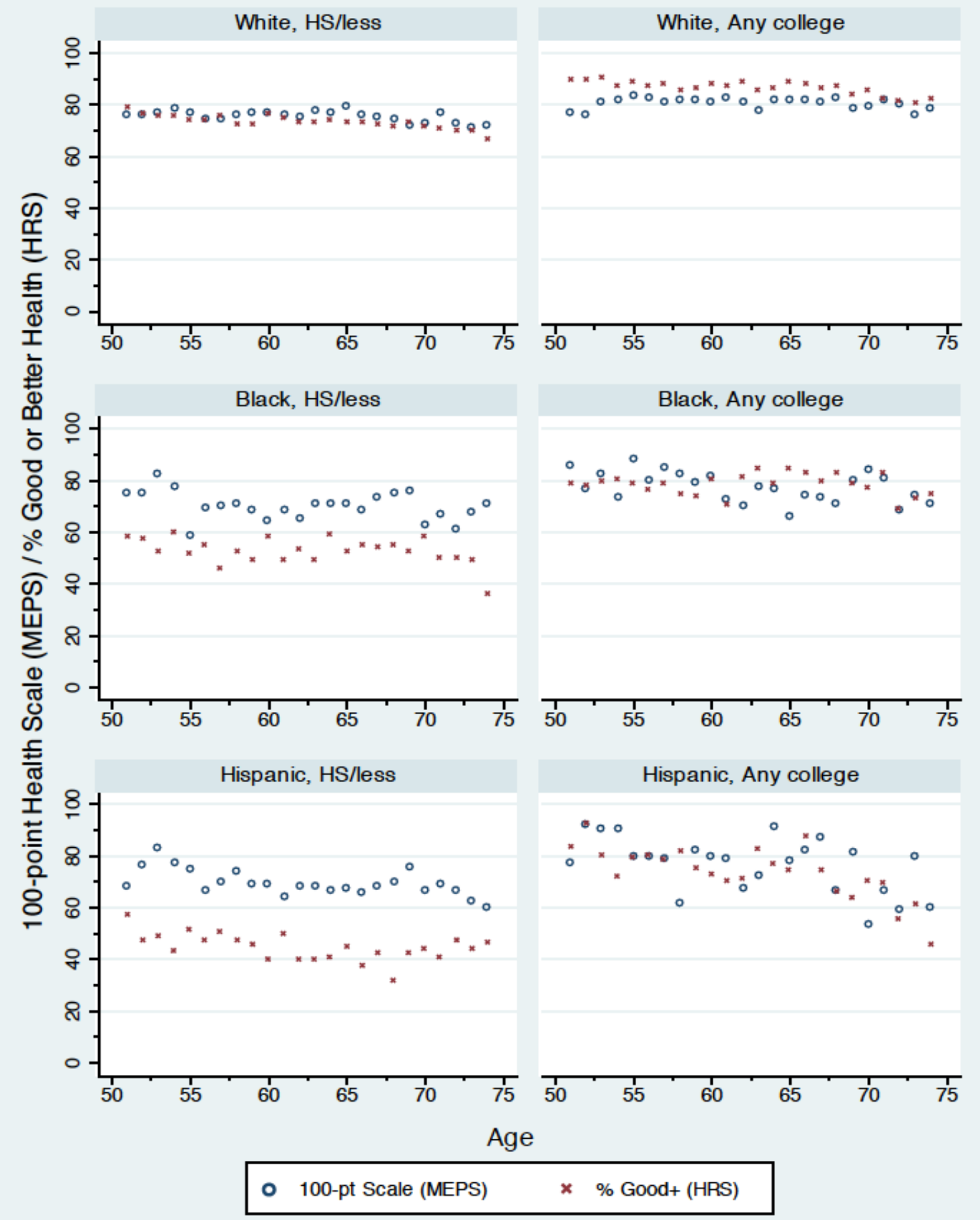

The chart shows the average thermometer score by age and demographic group in the MEPS (age 55-84), and the share of people reporting good, very good, or excellent health in the HRS (age 55-74). All data are weighted to national totals. 
Figure 3: Probability of Labor Force Participation and Disability by Health Status in the 2000-2003 MEPs, ages 57-61
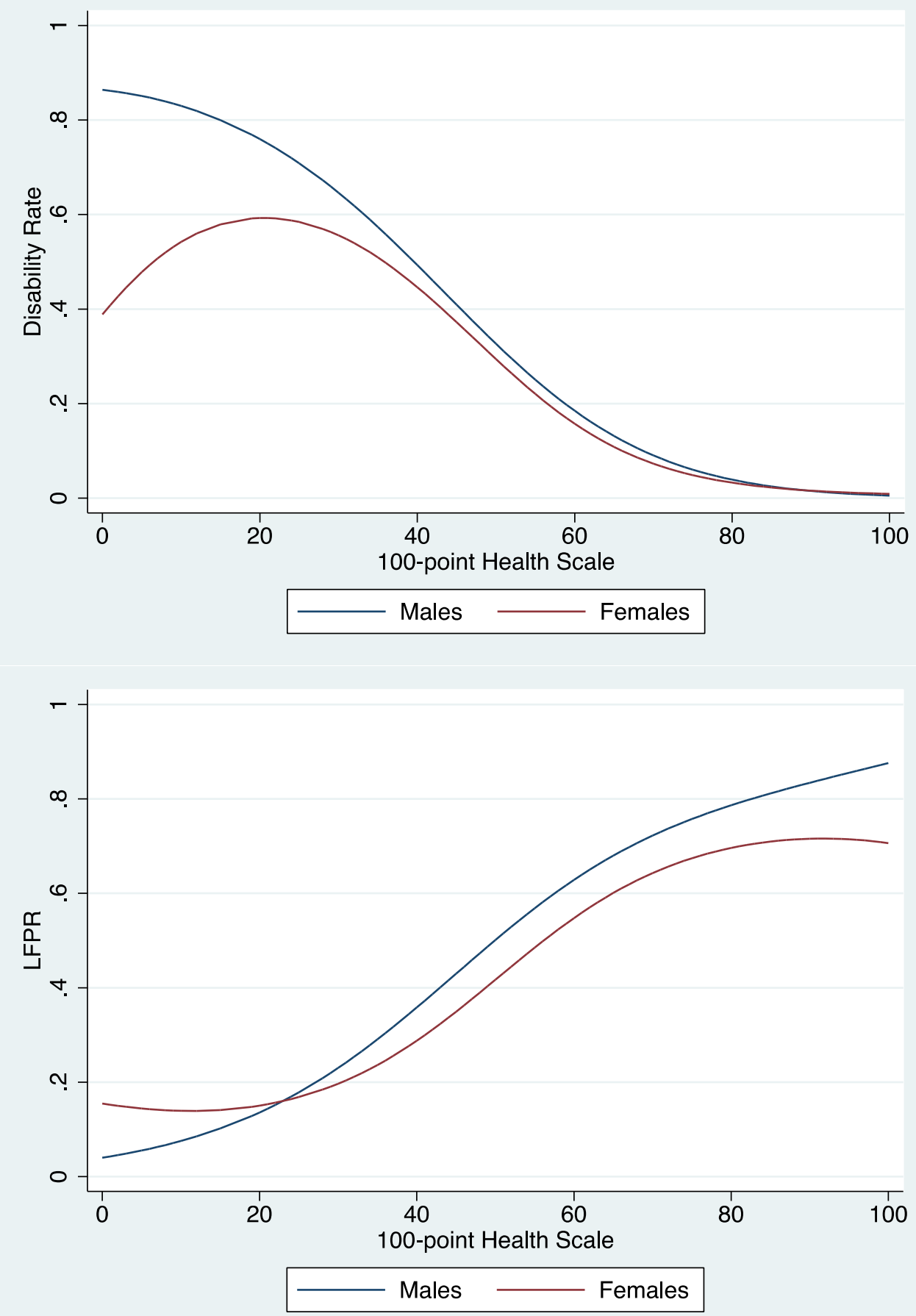

The chart shows rates of disability and labor force participation by health status. 
Figure 4: Probability of Labor Force Participation and Disability by Self-Reported Health Status in the HRS, ages 59-61

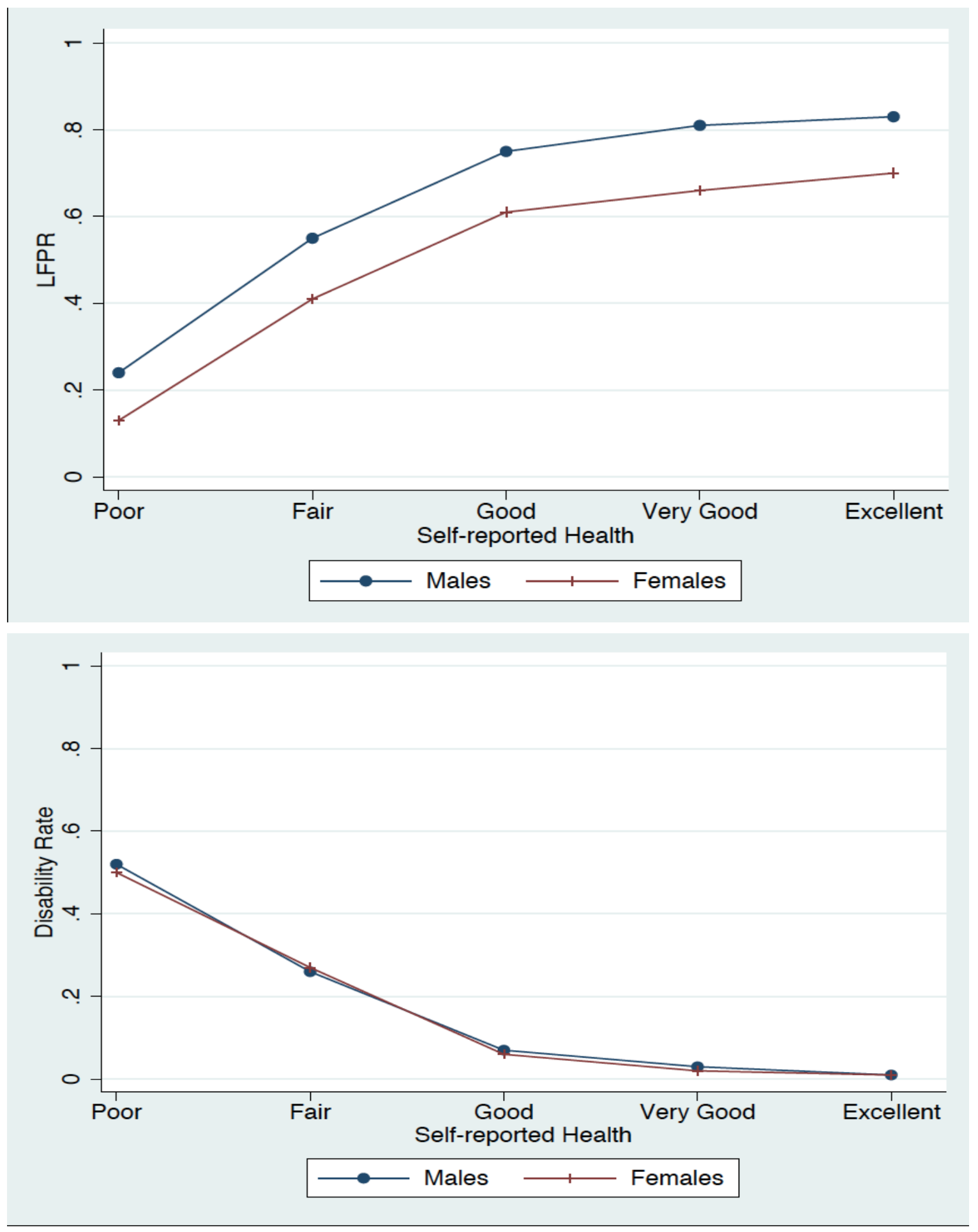

The chart shows rates of disability and labor force participation by health status. 
Figure 5: Change in Work Capacity for Population Aged 62-64

(a) Change in Probability of Being in the Labor Force, Assuming Early Eligibility Age is 65

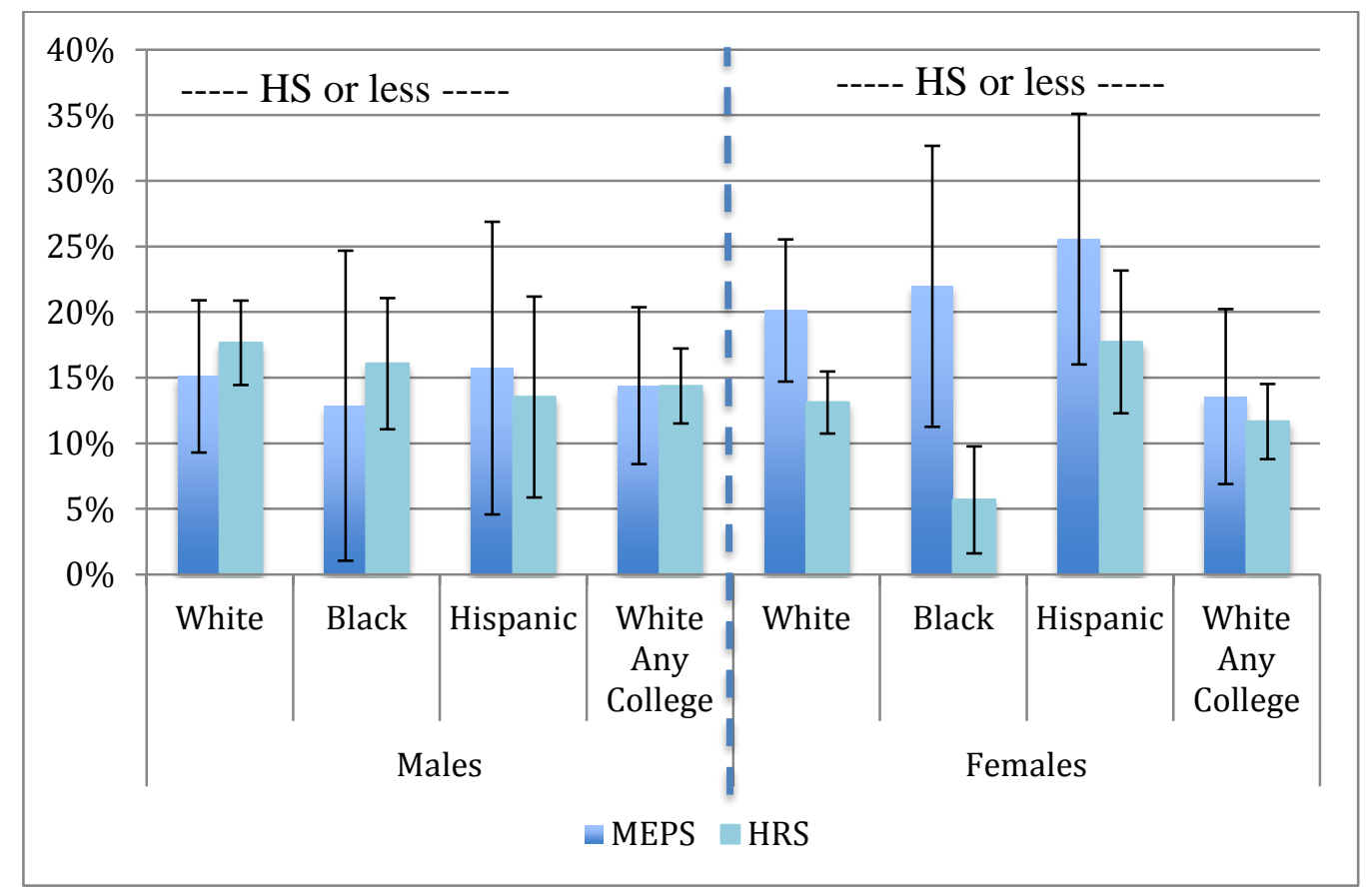

(b) Change in Probability of Being Disabled, Assuming Early Eligibility Age is 65

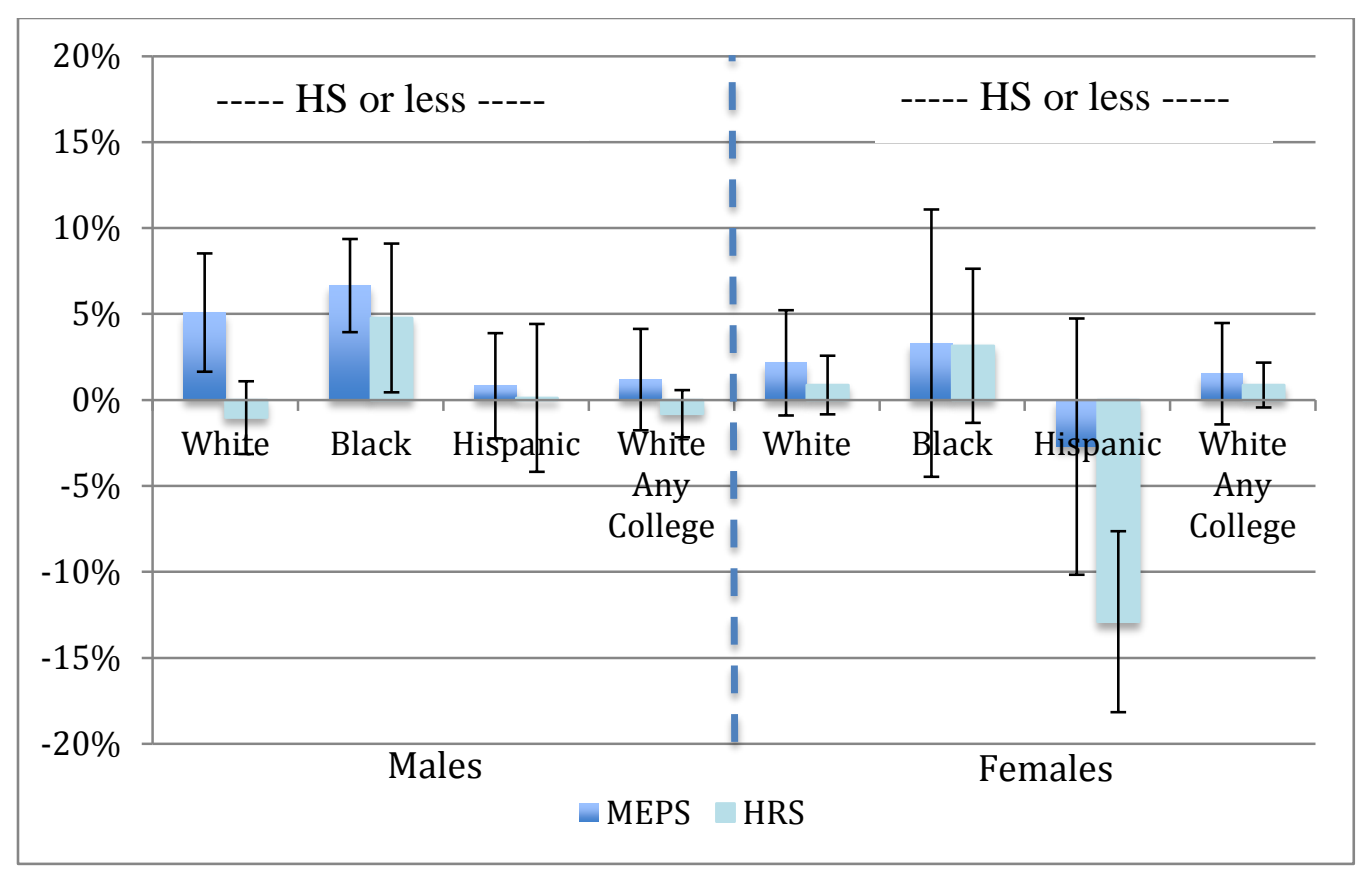

The figure shows the predicted increase in labor force participation and self-reported disability for people aged 62-64 based on the relationship between health and labor force status for people aged 57-61 (MEPS) and 59-61 (HRS). 
Table 1: Descriptive Statistics for Labor Force Status and Health

\begin{tabular}{|c|c|c|c|c|c|c|c|c|}
\hline & \multicolumn{4}{|c|}{ MEPS, 2000-2003 } & \multicolumn{4}{|c|}{ HRS, 1994-2008 } \\
\hline & $57-61$ & $62-64$ & 65-69 & 70-74 & $59-61$ & $62-64$ & $65-69$ & 70-74 \\
\hline \multicolumn{9}{|l|}{ OUTCOMES } \\
\hline \multicolumn{9}{|l|}{ Labor force status } \\
\hline In labor force & 0.69 & 0.51 & 0.32 & 0.17 & 0.64 & 0.49 & 0.35 & 0.21 \\
\hline Retired & 0.22 & 0.41 & 0.63 & 0.78 & 0.26 & 0.41 & 0.59 & 0.75 \\
\hline Disabled & 0.09 & 0.08 & 0.05 & 0.04 & 0.10 & 0.11 & 0.06 & 0.03 \\
\hline \multicolumn{9}{|c|}{ INDEPENDENT VARIABLES } \\
\hline \multicolumn{9}{|c|}{ Self-reported health } \\
\hline 100-point scale & $78(19)$ & $76(19)$ & $77(18)$ & $74(19)$ & --- & --- & --- & --- \\
\hline Excellent & -- & -- & -- & -- & 0.16 & 0.14 & 0.13 & 0.11 \\
\hline Very good & --- & --- & --- & --- & 0.33 & 0.33 & 0.32 & 0.31 \\
\hline Good & --- & --- & --- & --- & 0.29 & 0.31 & 0.32 & 0.33 \\
\hline Fair & --- & --- & --- & --- & 0.16 & 0.16 & 0.17 & 0.18 \\
\hline Poor & --- & --- & --- & --- & 0.07 & 0.06 & 0.06 & 0.07 \\
\hline \multicolumn{9}{|l|}{ Limitations } \\
\hline ADLs & 0.02 & 0.02 & 0.03 & 0.04 & 0.11 & 0.11 & 0.11 & 0.12 \\
\hline IADLs & 0.03 & 0.04 & 0.04 & 0.08 & 0.04 & 0.04 & 0.04 & 0.05 \\
\hline Vision impairment & 0.07 & 0.07 & 0.08 & 0.09 & --- & --- & --- & --- \\
\hline Hearing impairment & 0.12 & 0.11 & 0.15 & 0.19 & --- & --- & --- & --- \\
\hline Physical limitation & 0.17 & 0.19 & 0.20 & 0.28 & --- & --- & --- & --- \\
\hline Cognitive limitation & 0.04 & 0.05 & 0.04 & 0.07 & --- & --- & --- & --- \\
\hline Social limitation & 0.06 & 0.07 & 0.06 & 0.08 & --- & --- & --- & --- \\
\hline 1 Physical limitation & --- & --- & --- & --- & .177 & 0.18 & 0.19 & 0.19 \\
\hline >1 Physical limitation & --- & --- & --- & --- & .390 & 0.40 & 0.41 & 0.46 \\
\hline CES-D depression (0-8) & --- & --- & --- & --- & 1.41 & 1.28 & 1.27 & 1.33 \\
\hline
\end{tabular}


Table 1: Descriptive Statistics for Labor Force Status and Health

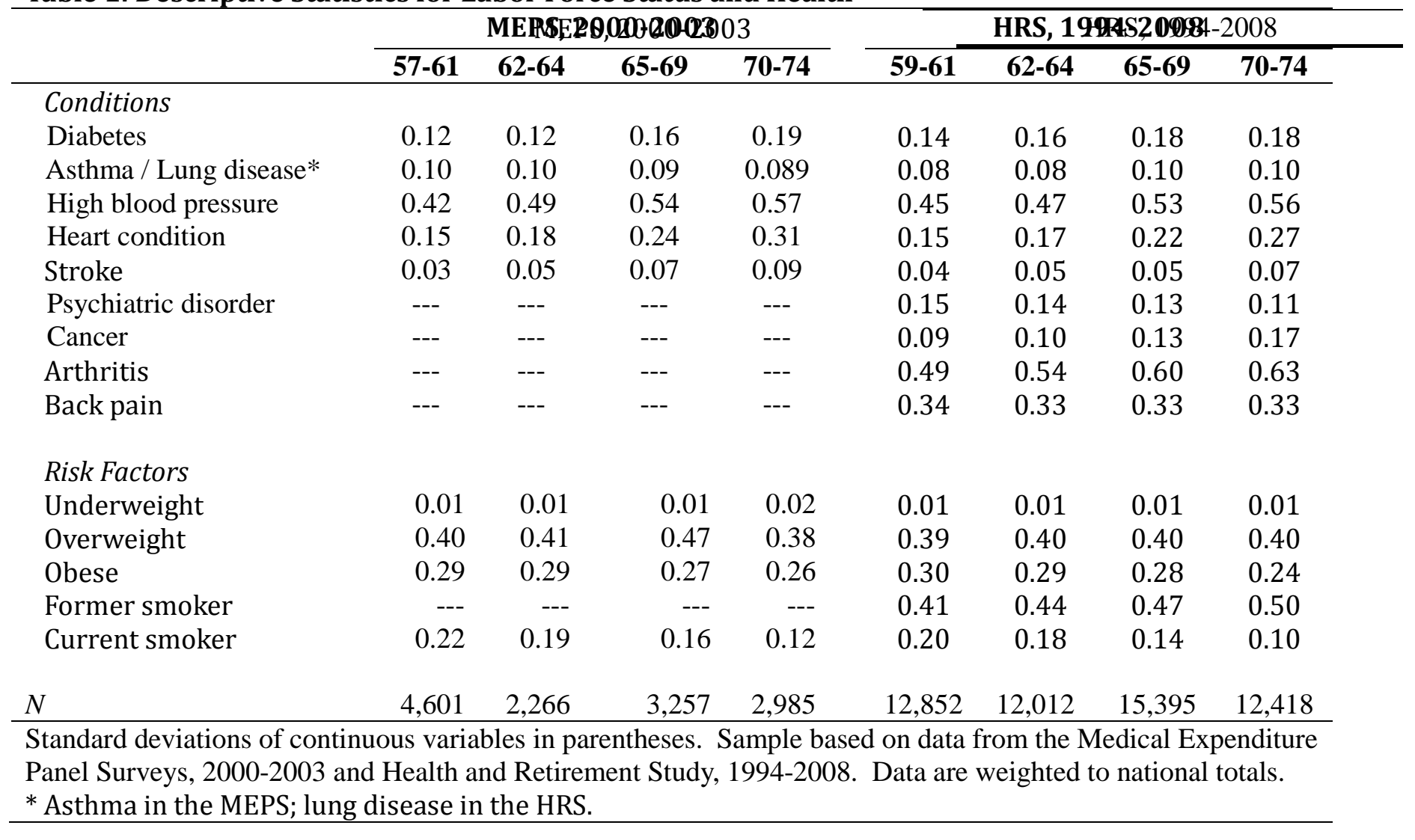


Table 2: Average Earnings for Workers Age 62-64 and Predicted Earnings of Non-workers (Respondents reporting 12 or fewer years education)

\begin{tabular}{|c|c|c|c|c|c|c|}
\hline & \multicolumn{3}{|c|}{ Males } & \multicolumn{3}{|c|}{ Females } \\
\hline & White & Black & Hispanic & White & Black & Hispanic \\
\hline $\begin{array}{l}\text { Earnings of current workers } \\
\text { (Standard Error) }\end{array}$ & $\begin{array}{c}\$ 33,239 \\
(1,070)\end{array}$ & $\begin{array}{l}\$ 31,167 \\
(1,492)\end{array}$ & $\begin{array}{l}\$ 25,989 \\
(1,583)\end{array}$ & $\begin{array}{r}\$ 21,702 \\
(653)\end{array}$ & $\begin{array}{r}\$ 16,998 \\
(846)\end{array}$ & $\begin{array}{l}\$ 17,773 \\
(1,363)\end{array}$ \\
\hline $\begin{array}{l}\text { Predicted earnings, nonworkers } \\
\text { (Standard Error) }\end{array}$ & $\begin{array}{l}28,176 \\
(1,990)\end{array}$ & $\begin{array}{l}23,457 \\
(3,063)\end{array}$ & $\begin{array}{l}29,910 \\
(6,232)\end{array}$ & $\begin{array}{r}17,362 \\
(816)\end{array}$ & $\begin{array}{r}14,150 \\
(1,162)\end{array}$ & $\begin{array}{l}14,205 \\
(1,618)\end{array}$ \\
\hline $\begin{array}{l}\text { Workers - nonworkers } \\
\text { (Standard Error) } \\
\text { \% difference }\end{array}$ & $\begin{array}{c}5,063 \\
(1,925) \\
15 \%\end{array}$ & $\begin{array}{c}7,710 \\
(2,885) \\
25 \%\end{array}$ & $\begin{array}{c}-3,921 \\
(5,989) \\
-15 \%\end{array}$ & $\begin{array}{r}4,340 \\
(753) \\
20 \%\end{array}$ & $\begin{array}{r}2,848 \\
(823) \\
17 \%\end{array}$ & $\begin{array}{r}3,569 \\
(1,339) \\
20 \%\end{array}$ \\
\hline
\end{tabular}

Note: Earnings are expressed in constant 2002 dollars. Standard errors of predicted earnings for non-workers and the difference between earnings of workers and non-workers were obtained using bootstrapping techniques, based on parameter estimates from generalized linear models of earnings for workers aged 62-64. The predicted wage for current non-workers is weighted by the predicted probability of being in the labor force (based on the work capacity models). The difference in median earnings observed - predicted was 1,335 (4.5\%), 7,119 (26\%), and 1,658 (7.4\%) for male whites, blacks, and Hispanics, respectively. For women the same figures are: 5,227 (28\%), 4,063 (30\%) and 4,211 (31\%). 
Table 3: Expected Retirement Years, and Social-Security Eligible Retirement Years, at Age 62, Whites

\begin{tabular}{|c|c|c|c|c|}
\hline & \multicolumn{2}{|c|}{ Males } & \multicolumn{2}{|c|}{ Females } \\
\hline & HS or less & Any college & HS or less & Any college \\
\hline \multicolumn{5}{|l|}{ Observed: } \\
\hline Expected Retirement Years & 11.7 & 14.9 & 16.3 & 18.8 \\
\hline \multicolumn{5}{|l|}{ Raise EEA to 65: } \\
\hline Expected Retirement Years & 11.1 & 14.4 & 15.7 & 18.3 \\
\hline Simulated-actual & -0.6 & -0.5 & -0.7 & -0.5 \\
\hline Percent difference & $-5.2 \%$ & $-3.3 \%$ & $-4.0 \%$ & $-2.6 \%$ \\
\hline $\begin{array}{l}\text { Social-Security eligible } \\
\text { Expected Retirement Years* }\end{array}$ & 10.7 & 13.9 & 14.8 & 17.6 \\
\hline Simulated-actual & -1.0 & -1.0 & -1.5 & -1.2 \\
\hline Percent difference & $-8.9 \%$ & $-6.7 \%$ & $-9.2 \%$ & $-6.5 \%$ \\
\hline
\end{tabular}

* Social-Security Eligible Expected Retirement Years counts expected retirement years at ages 65 and up, based on the higher EEA. 


\section{APPENDIX}

Table A1: Descriptive Statistics for Demographic Variables

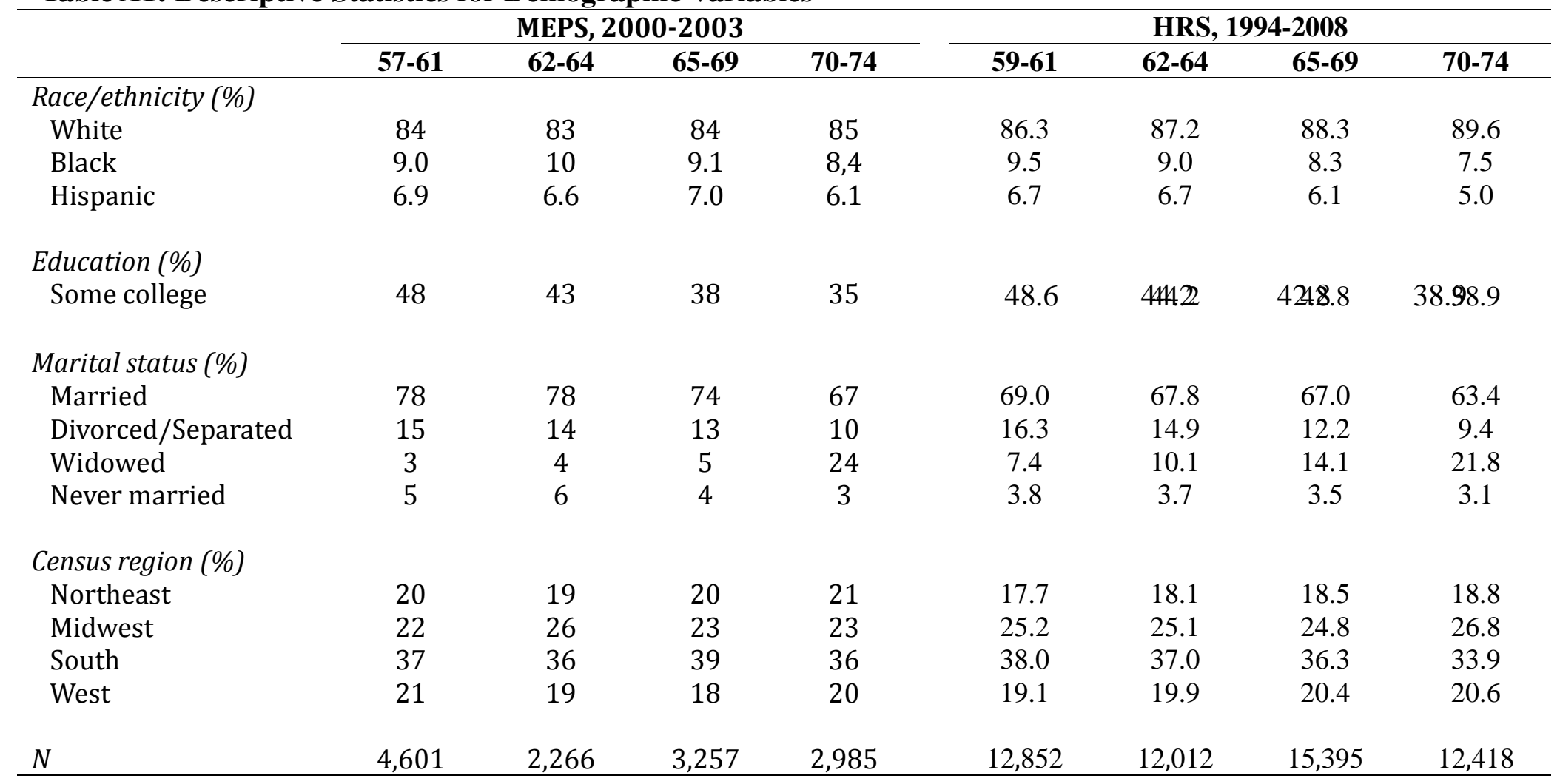


Table A2: Relative Risk Ratios for Labor Force Status in the 2000-2003 MEPS

\begin{tabular}{|c|c|c|c|c|}
\hline \multirow[b]{3}{*}{ Variable } & \multicolumn{4}{|c|}{ Ages 57-61 } \\
\hline & \multicolumn{2}{|c|}{ Males } & \multicolumn{2}{|c|}{ Females } \\
\hline & Disabled & Retired & Disabled & Retired \\
\hline \multicolumn{5}{|l|}{ 100-point health scale (/10): } \\
\hline -linear term & $0.51 * * *$ & $0.90 *$ & $0.56 * * *$ & 0.93 \\
\hline -squared term & 0.98 & 0.98 & 1.03 & $1.05 * *$ \\
\hline -cubic term & 1.00 & 0.99 & 1.01 & 1.00 \\
\hline ADLs/IADLs & $6.24 * * *$ & $3.43^{* *}$ & 1.64 & $1.95 *$ \\
\hline Vision Impairment & 1.68 & 1.33 & $1.63^{*}$ & 0.99 \\
\hline Hearing Impairment & 0.81 & 1.21 & 1.50 & $1.50 *$ \\
\hline Physical Lim. & $2.53 * * *$ & 1.37 & $4.63 * * *$ & $1.42 * *$ \\
\hline Cognitive lim. & 1.69 & 0.85 & $2.05^{*}$ & 1.48 \\
\hline Social lim. & $2.69 * *$ & $2.79 * * *$ & $2.17 * *$ & 1.64 \\
\hline Diabetes & 1.02 & $0.61 *$ & $1.87 * *$ & $1.63 * *$ \\
\hline Asthma & 1.63 & 1.29 & 0.93 & 1.01 \\
\hline High BP & 0.92 & 0.98 & 1.44 & 1.09 \\
\hline Heart condition & $2.17 * * *$ & $1.45^{*}$ & 1.23 & 0.79 \\
\hline Stroke & $3.04 * *$ & 1.07 & 2.02 & 1.31 \\
\hline Some college & $0.42^{* * *}$ & 1.10 & $0.47 * * *$ & $0.76^{* *}$ \\
\hline Black & 1.53 & 1.26 & 0.86 & 0.84 \\
\hline Hispanic & 0.92 & 0.87 & 0.96 & $1.43^{*}$ \\
\hline $\begin{array}{l}\text { Divorced, separated or } \\
\text { widowed }\end{array}$ & $2.31^{* * *}$ & 1.02 & 1.03 & $0.30 * * *$ \\
\hline Never married & $5.47 * * *$ & 1.59 & $4.17 * * *$ & 0.59 \\
\hline Metropolitan area & $2.24 * * *$ & 1.06 & 0.82 & 1.00 \\
\hline $\mathrm{N}$ & & 29 & & 472 \\
\hline
\end{tabular}

Risk ratios reflect multinomial logit models of reporting disability or retirement, relative to being in the labor force. Models include dummies for region. $\mathrm{p}$-values: ${ }^{*} \mathrm{p}<.1 ;{ }^{* *} \mathrm{p}<.05 ;{ }^{* * *} \mathrm{p}<.01$ 
Table A3: Relative Risk Ratios for Labor Force Status in the HRS

\begin{tabular}{|c|c|c|c|c|}
\hline \multirow[b]{3}{*}{ Variable } & \multicolumn{4}{|c|}{ Ages 59-61 } \\
\hline & \multicolumn{2}{|c|}{ Males } & \multicolumn{2}{|c|}{ Females } \\
\hline & Disabled & Retired & Disabled & Retired \\
\hline \multicolumn{5}{|c|}{ Self-reported Health (Excellent is ref) } \\
\hline Very Good & $1.99 *$ & 0.99 & 0.65 & 1.07 \\
\hline Good & $2.44^{* *}$ & 1.00 & 1.30 & 0.95 \\
\hline Fair & $5.84 * * *$ & 1.17 & $3.18^{* * *}$ & 0.97 \\
\hline Poor & $10.0^{* * *}$ & $2.61^{* * *}$ & $9.51^{* * *}$ & $2.35^{* * *}$ \\
\hline \multicolumn{5}{|l|}{ Limitations in activity \& function } \\
\hline \multicolumn{5}{|l|}{ Physical functional limits } \\
\hline Exactly 1 limitation & $2.51^{* * *}$ & 1.08 & 1.50 & 1.09 \\
\hline More than 1 limitation & $6.07^{* * *}$ & $1.35^{* *}$ & $5.80^{* * *}$ & $1.19 *$ \\
\hline Any ADL limitations & $1.81^{* * *}$ & 1.21 & $2.16^{* * *}$ & $1.76^{* * *}$ \\
\hline Any IADL limitations & $2.26^{* * *}$ & 1.40 & $1.88^{* *}$ & 1.08 \\
\hline CES-D depression score (0-8) & 0.95 & $0.96^{* * *}$ & 1.05 & $1.05^{* *}$ \\
\hline \multicolumn{5}{|l|}{ Conditions } \\
\hline Heart disease & $2.12^{* * *}$ & $1.39 * * *$ & $1.80^{* * *}$ & 1.49 \\
\hline Lung disease & $1.51^{* *}$ & 0.82 & 1.21 & 1.07 \\
\hline Stroke & $2.48^{* *}$ & $1.94^{* * *}$ & 1.63 & 1.01 \\
\hline Psychiatric disorder & $1.74^{* *}$ & 0.97 & $1.79 * * *$ & 1.38 \\
\hline Cancer & 0.96 & 1.03 & 1.09 & 1.20 \\
\hline Hypertension & $1.52^{* *}$ & $1.21^{*}$ & 0.77 & 1.00 \\
\hline Arthritis & 1.34 & 1.00 & 1.13 & 1.13 \\
\hline Diabetes & 0.85 & 1.07 & $1.54^{* *}$ & 1.38 \\
\hline Back pain & 1.00 & 1.09 & 1.12 & 0.93 \\
\hline \multicolumn{5}{|l|}{ Risk factors } \\
\hline Underweight & 0.98 & 2.44 & 0.68 & 1.17 \\
\hline Overweight & 0.85 & 0.97 & 0.80 & 0.97 \\
\hline Obese & 1.02 & 0.97 & 1.08 & 0.95 \\
\hline Former smoker & 1.27 & 1.10 & 0.99 & 1.00 \\
\hline Current smoker & 1.40 & 1.21 & 1.07 & 0.88 \\
\hline \multicolumn{5}{|l|}{ Demographics } \\
\hline$<$ High school degree & 0.85 & $0.69 * *$ & 1.31 & $1.34^{* *}$ \\
\hline Some college & $0.37^{* * *}$ & 0.87 & 0.86 & $0.82^{*}$ \\
\hline College degree or more & $0.62^{*}$ & $0.75^{*}$ & 0.62 & 0.91 \\
\hline Hispanic ethnicity & $0.32^{* * *}$ & 1.01 & 0.73 & 0.95 \\
\hline Black, non-Hispanic & $2.18^{* * *}$ & 1.08 & $2.09 * * *$ & 1.19 \\
\hline Other Nonwhite race & 0.93 & 0.66 & 1.09 & $1.68^{* *}$ \\
\hline
\end{tabular}


Table A3 (continued)

\begin{tabular}{lllll}
\hline & \multicolumn{3}{c}{ Ages 59-61 } \\
\cline { 2 - 5 } Variable & \multicolumn{2}{c}{ Males } & \multicolumn{2}{c}{ Females } \\
\cline { 2 - 5 } Household composition & Disabled & Retired & Disabled & Retired \\
$\quad$ Single & 1.01 & 0.79 & $0.64^{* *}$ & $0.44^{* * *}$ \\
Married, working spouse & $0.61^{* * *}$ & $0.32^{* * *}$ & $0.34^{* * *}$ & $0.42^{* * *}$ \\
2 non-married adults in house & 1.11 & 0.74 & 1.22 & 0.80 \\
3-4 household members & 1.05 & 0.88 & $0.69^{* *}$ & 0.91 \\
4+ household members & 0.81 & 0.77 & 0.74 & 0.83 \\
& & & & \\
Economics & & & & \\
$\quad$ Blue collar, longest job & 1.12 & 1.07 & 1.01 & $0.63^{* * *}$ \\
$\quad$ Low-skilled services, longest & 0.91 & 1.23 & $0.40^{* * *}$ & $0.40^{* * *}$ \\
$\quad$ Has own health insurance & $0.18^{* * *}$ & 0.86 & $0.22^{* * *}$ & $0.42^{* * *}$ \\
Health insurance from spouse & $0.55^{* * *}$ & 1.24 & $0.68^{* *}$ & $1.59^{* * *}$ \\
$\quad$ Covered by a pension & $0.56^{* * *}$ & $0.61^{* * *}$ & $0.26^{* * *}$ & $0.27^{* * *}$ \\
& & & & 7,403 \\
\hline
\end{tabular}

Risk ratios reflect multinomial logit models of reporting disability or retirement, relative to being in the labor force. Models include dummies for census region and survey wave. p-values: ${ }^{*} \mathrm{p}<.1$; ${ }^{* *} \mathrm{p}<.05 ;{ }^{* * *} \mathrm{p}<.01$. 
Table A4: Change in Probability of Labor Force Status (\%)

\begin{tabular}{|c|c|c|c|c|}
\hline & & & $\begin{array}{c}\text { In labor } \\
\text { force }\end{array}$ & Disabled \\
\hline \multicolumn{5}{|c|}{ MEPS data } \\
\hline \multirow[t]{4}{*}{ Men } & HS or less & White & 15 & 6 \\
\hline & & Black & 12 & 6 \\
\hline & & Hispanic & 21 & 0 \\
\hline & Some college & White & 15 & 2 \\
\hline \multirow[t]{4}{*}{ Women } & HS or less & White & 19 & 4 \\
\hline & & Black & 15 & 3 \\
\hline & & Hispanic & 27 & -2 \\
\hline & Some college & White & 15 & 2 \\
\hline \multicolumn{5}{|l|}{ HRS data } \\
\hline \multirow[t]{6}{*}{ Men } & HS or less & White & 18 & -1 \\
\hline & & Black & 16 & 5 \\
\hline & & Hispanic & 14 & 0 \\
\hline & Some college & White & 14 & -1 \\
\hline & & Black & 10 & -4 \\
\hline & & Hispanic & 11 & -4 \\
\hline \multirow[t]{6}{*}{ Women } & HS or less & White & 13 & 1 \\
\hline & & Black & 5.7 & 3 \\
\hline & & Hispanic & 18 & -13 \\
\hline & Some college & White & 12 & 1 \\
\hline & & Black & 20 & -6 \\
\hline & & Hispanic & 20 & -9 \\
\hline
\end{tabular}

